Article

\title{
Detection and Identification of Remnant PFM-1 'Butterfly Mines' with a UAV-Based Thermal-Imaging Protocol
}

\author{
Alex Nikulin *, Timothy S. de Smet, Jasper Baur, William D. Frazer and Jacob C. Abramowitz \\ Department of Geological Sciences and Environmental Studies, Binghamton University-The State University of \\ New York, Binghamton, NY 13902, USA; tdesmet@binghamton.edu (T.S.d.S.); jbaur1@binghamton.edu (J.B.); \\ wfrazer1@binghamton.edu (W.D.F.); jabramo2@binghamton.edu (J.C.A.) \\ * Correspondence: anikulin@binghamton.edu
}

Received: 27 August 2018; Accepted: 19 October 2018; Published: 23 October 2018

\begin{abstract}
Use of landmines as a weapon of unconventional warfare rapidly increased in armed conflicts of the last century and some estimates suggest that at least 100 million remain in place across post-conflict nations. Among munitions and explosives of concern (MECs), aerially deployed plastic anti-personnel mines are particularly challenging in terms of their detection and subsequent disposal. Detection and identification of MECs largely relies on the geophysical principles of magnetometry and electromagnetic-induction (EMI), which makes non-magnetic plastic MECs particularly difficult to detect and extremely dangerous to clear. In a recent study we demonstrated the potential of time-lapse thermal-imaging technology to detect unique thermal signatures associated with plastic MECs. Here, we present the results of a series of field trials demonstrating the viability of low-cost unmanned aerial vehicles (UAVs) equipped with infrared cameras to detect and identify the most notorious plastic landmines-the Soviet-era PFM-1 aerially deployed antipersonnel mine. We present results of an experiment simulating analysis of a full-scale ballistic PFM-1 minefield and demonstrate our ability to accurately detect and identify all elements associated with this type of deployment. We report significantly reduced time and equipment costs associated with the use of a UAV-mounted infrared system and anticipate its utility to both the scientific and non-governmental organization (NGO) community.
\end{abstract}

Keywords: remote sensing; unmanned aerial vehicle (UAV); thermal imaging; landmines

\section{Introduction}

Since their initial inception in the 19th century and mass-use in conflicts of the 20th century, landmines have become synonymous with modern warfare. While early landmines were designed with enough explosive charge to kill an enemy combatant or disable an armored vehicle, a calculated lowering of explosive charges occurred over time, with antipersonnel landmines becoming primarily maiming devices. In this capacity, the logic of modern warfare dictated that a single landmine would disable multiple enemies - the victim and those forced to tend to their injuries [1]. In parallel, as large-scale conflicts of the early 20th century gave way to regional and civil conflicts in the latter half of the century and into the new century, landmines largely became a weapon of unconventional warfare with disorganized placement of minefields and individual explosive devices [2]. Recent studies suggest that there are more than 100 million remnant landmines in place across post-conflict regions [3] and even with recent efforts to curb their use, 10 mines are placed for every mine removed [4]. Efforts to clear landmines are significantly hampered by evolved landmine technology, specifically the increased use of plastic in landmine design, making their detection using traditional electromagnetic-induction (EMI) methods particularly difficult [1,5]. 
The mass-produced Soviet PFM-1 anti-personnel landmines represent a cruel apex of landmine technology driven by the two development vectors of decreased explosive capacity and increased difficulty of detection (Figure 1). The small liquid explosive charge of this landmine is fully encased in a low-visibility plastic body and the mines are dispersed from an aircraft or special artillery shells [6,7]. The designated purpose of the PFM-1 is to cause indiscriminate traumatic injury with the irreversible trigger set at $\sim 5 \mathrm{~kg}$ [8]. The design of the mine combined with a low triggering weight have earned it the nickname of "the toy mine" due to a high casualty rate among small children who find these devices while playing and who are the primary victims of the PFM-1 in post-conflict nations, like Afghanistan [9]. In Afghanistan the situation is particularly dire, as over a million of these mines remain in place following the indiscriminate and unaccounted use of PFM-1 mines during the decade-long Soviet-Afghan conflict [10,11]. During this conflict, PFM-1 minefields were set up to block high-altitude mountain passes and these minefields have since remained in place, with limited active efforts to mitigate the problem due to high costs associated with accessing and demining high-altitude remote areas $[12,13]$. Further complicating the problem is the apparent "migration" of individual PFM-1 elements that may become mobile when impacted by seasonal melt water due to their low mass and may be moved considerable distances from their initial deployment areas.

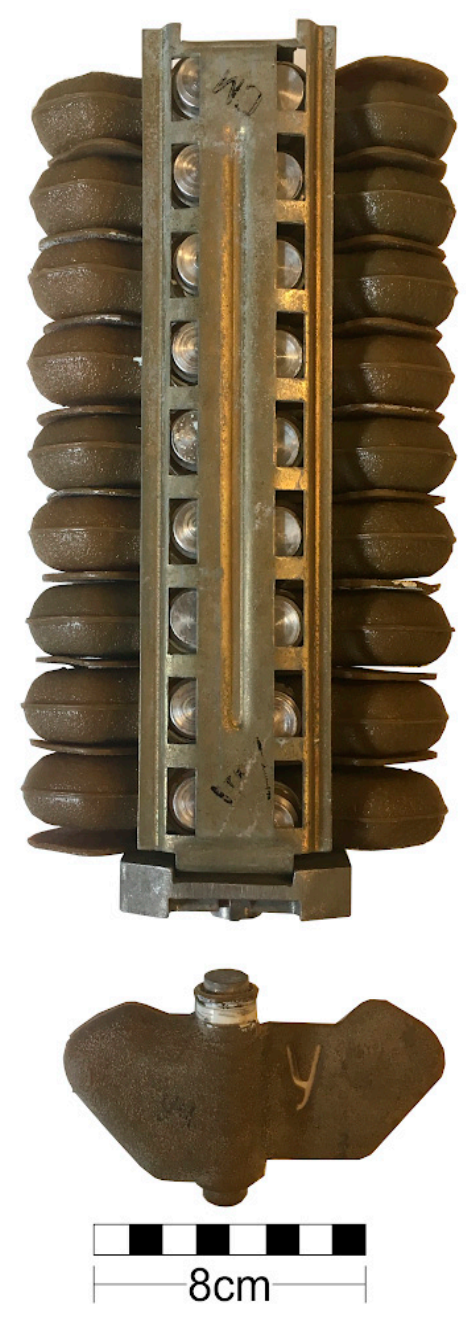

Figure 1. The lightweight $75 \mathrm{~g}$ PFM-1 plastic landmine (bottom) and the loaded 18-mine aluminum KSF cassete (top).

The polyethylene-body design of the PFM-1 and other aerially-deployed landmines makes them particularly difficult to detect using traditional EMI methods used for larger metal munitions and explosives of concern (MECs) [14-16]. Decreased use of metal in the design of landmines such as the 
PFM-1 forces an operator of an EMI metal detector to increase the sensitivity of their instrument, leading to an increased number of false positives that dramatically slows down the process of clearing an impacted area [17]. As a consequence, a number of alternative geophysical detection techniques have been tested with varying degrees of operational success. Notably, studies focused on ground-penetrating radar (GPR), acoustic-seismic (A/S) coupling profiling, and infrared (IR) imaging techniques demonstrated potential in detection and identification of buried and surface landmines, with IR imagery being particularly adaptable for remote detection of small aerially-deployed landmines, such as the PFM-1.

GPR demonstrated considerable potential in detecting non-metallic objects at depth [18] and a number of studies demonstrated its applicability in landmine detection effort [19-22]. Furthermore, because radar waves are sensitive to dielectric constant variations of the subsurface, GPR can be used to classify buried objects and characterize soil properties [23-25]. However, a number of limitations of GPR surveys in application to landmine detection have also emerged, including prohibitive false alarm rates and prolonged acquisition and processing times needed to collect non-aliased 3D datasets required for identification of smaller landmines [18,26]. In a recent study, focused specifically on GPR-based detection of PFM-1 landmine targets, Lombardi et al. [22] demonstrated that under laboratory conditions, which featured direct sensor contact with the ground surface, optimal landmine orientation and soil properties, high-resolution GPR could not reliably identify the characteristic shape of the PFM-1 and reliably detect or classify this MEC type.

A/S coupling investigations are driven by interpretation of reflected compressional waves from buried objects at depth and are sensitive to variations in velocity and density contrasts of the subsurface. A number of studies focused on high-resolution seismic profiling in landmine detection with some encouraging results in detection of larger landmine targets, like anti-tank mines [27] and larger antipersonnel mines [28]. A/S coupling studies utilize seismic energy that is generated as an acoustic wave field and is converted to seismic waves at the air-surface interface and have the advantage in terms of energy source placement above the surface and a resulting lower risk of MEC detonation. A number of A/S studies utilizing laser doppler vibrometer (LDV) technology demonstrated their overall effectiveness in detection and classification of larger objects at depth [29-31]. However, A/S studies are inherently limited by the lower resolution associated with longer-wavelength seismic waves and have not been demonstrated to be effective in detection of small anti-personnel landmines, like the PFM-1. The small size, variable orientation, and low $(\sim 5 \mathrm{~kg})$ triggering weight of the PFM-1 does not allow for these methods to be successfully applied in the field.

IR imaging has been successfully applied in a variety of remote-sensing applications in the past. These applications include aircraft- and satellite-based monitoring of water temperatures [32,33], ice thickness [34], large storms [35,36] and animal populations [37]. As low-altitude unmanned aerial vehicle (UAV) technology has become more accessible, the improved resolution from these platforms has allowed for detailed studies of targets which were previously undetectable in higher-altitude wide-area surveys. Multiple studies relying on UAV-based IR imagery have focused on agricultural and forest management [38-41], volcano monitoring [42,43], archeological investigations [44,45], and a variety of other applications [46]. Importantly, in recent years IR imagery has been used for the detection of subsurface targets. These studies have successfully shown that a thermal target can be identified from a moving vehicle platform [47,48]. IR imagery has also been used for the detection of targets from a manned aircraft platform [49]. Finally, IR imagery has previously been used in the detection of larger conventional landmines in static environments [50-53]. In our work, we draw inspiration from previous studies that focused on static, vehicle-based, and aircraft-based IR imaging experiments, including our own work outlined in de Smet and Nikulin [11] and in de Smet et al. [54].

We present the results of a field-test of a small low-altitude UAV platform that enabled dynamic collection and interpretation of high-resolution thermal imaging over a large area, ultimately allowing successful detection and identification of the small plastic PFM-1 landmines. The use of a UAV-platform significantly reduces the time, labor cost and risks associated with initial wide-area assessment 
of minefield presence, orientation and possible ballistic overlap of individual PFM-1 minefields. Our results point to the viability of this methodology as a supplemental technique to be used alongside other established methods, such as EMI surveys, as well as alternative techniques, such as GPR and A/S surveys.

\section{Materials and Methods}

Methodological limitations in PFM-1 detection are largely compensated for by labor- and cost-intensive manual surveys, particularly in areas inaccessible to large demining rollers and trawls. As a result, virtually no active efforts are in place to de-mine remote areas impacted by plastic landmines due to high associated costs and risks. An emerging geophysical methodology that has significant potential in plastic MEC detection is remote sensing of thermal anomalies associated with plastic MECs, specifically unique thermal inertia signatures. Thermal inertia is a measure of a material's resistance to temperature fluctuations and is a way to quantify variable responses to temperature change. Sabol et al. [55] demonstrated that differential apparent thermal inertia (DATI) can be used to estimate apparent thermal inertia (ATI) from short-term time-series data acquired with an inexpensive forward-looking infrared (FLIR) camera. A thermal infrared camera measures the amount of infrared radiation emitted by an object. Physical properties of materials such as specific heat capacity, thermal conductivity, composition, size, shape, density, and porosity affect the thermal behavior of objects so that varied materials heat and cool at different rates.

In a 2017 proof-of concept study, our research team developed and tested a new detection methodology focused on remotely assessing thermal infrared signatures of plastic landmines in stationary tests with a drone hovering at $2 \mathrm{~m}$ altitude [11]. Using the FLIR Vue Pro R, we measured the radiometric thermal infrared temperature in degrees Celsius and calculated the DATI to determine if long-wave thermal infrared (LWIR) photography is an applicable method to detect the PFM-1 plastic land mines. We demonstrated that the plastic casing of the PFM-1 and incorporation of a liquid explosive charge in its design generate a distinct thermal anomaly relative to the surrounding host environment. Furthermore, we established that the use of plastic casing and liquid explosives in the PFM-1 design significantly contributes to establishing a rate of heating and cooling of the mine that could be drastically different relative to surrounding host geology. Finally, we demonstrated that these contrasts in heating and cooling rates are most pronounced when temperature changes are high at sunrise and sundown. Our initial results indicated that remote assessment and cross-correlation of thermal inertia parameters over a large area could permit rapid detection of randomly dispersed plastic landmines with a high degree of accuracy and low associated costs.

We present the results of multi-day dynamic field trials where a $13 \mathrm{~mm}$ focal length FLIR Vue Pro R $(640 \times 512$ pixels $)$ LWIR camera was mounted to a low-cost (\$250) commercially available 3DR Solo quadcopter drone (Figure 2). This pilot study was conducted at Chenango Valley State Park, New York, in a flat former parking lot with low grass and rubble. This setting is environmentally similar to areas where the PFM-1 were dispersed in Afghanistan. Eighteen inert PFM-1 mines along with the aluminum KSF-1 casing were positioned in varying in-place orientations to mimic a ballistic ellipsoidal minefield of $10 \times 20 \mathrm{~m}$ maximum dimensions [11]. Four different orientations were chosen to determine if the in-place mine geometry affects the apparent temperature and thus the ability to detect and identify the mines (Figure 3). We complemented thermal imaging with a visual light aerial photography flight at $10 \mathrm{~m}$ altitude with a DJI Phantom 4 Professional 20-megapixel camera (Figure 4a), which resulted in $0.24 \mathrm{~cm} /$ pixel resolution photogrammetry model orthomosaic.

On the night of 16 September and morning of 17 September 2017, 28 identical preprogrammed Global Positioning System (GPS)-guided autonomous UAV flights were collected at 15 min intervals before and after sunrise and sunset using the pix4Dcapture application on an Android tablet computer linked to the 3DR radio controller via Wi-Fi. This interval was the shortest practical interval as determined by the survey parameters. Six transects were collected per flight at an altitude of approximately $10 \mathrm{~m}$ above ground level (Figure 3). A flight altitude of $10 \mathrm{~m}$ results in a $0.012 \mathrm{~m}$ ground 
sampling distance (pixel size resolution). This flight altitude was chosen as a good range-to-resolution trade-off as higher elevation flights decrease resolution while lower altitude flights require many more transects to achieve similar image overlap. To control for camera recalibration transmission errors during flights a TeAx ThermalCapture 2.0 OEM was used during data acquisition to collect 14-bit raw digital radiometric data with a $0.04{ }^{\circ} \mathrm{C} /$ pixel thermal resolution.

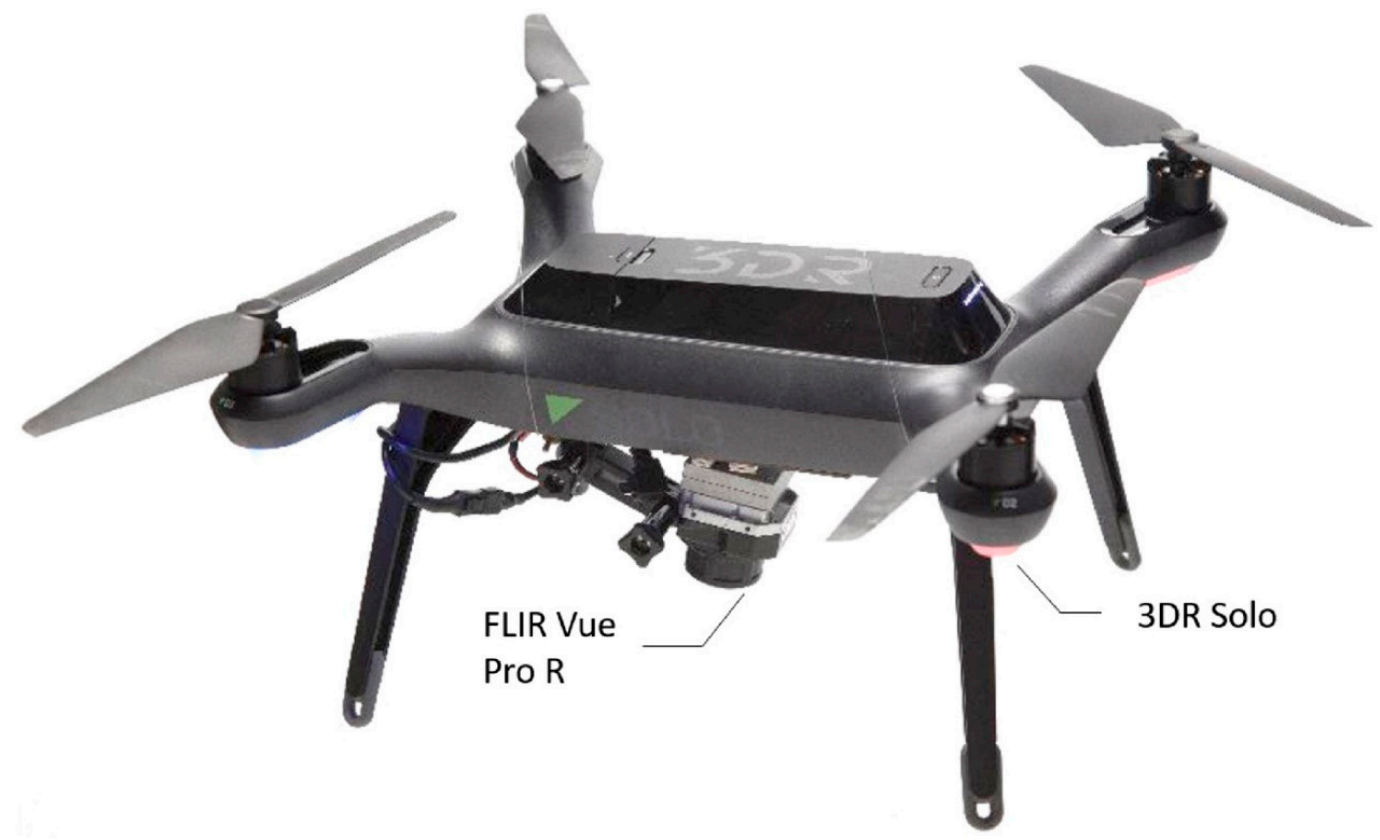

Figure 2. Low-cost commercially available materials used in this study, 3DR Solo quadcopter unmanned aerial vehicle (UAV) with attached forward-looking infrared (FLIR) Vue Pro R thermal infrared camera.

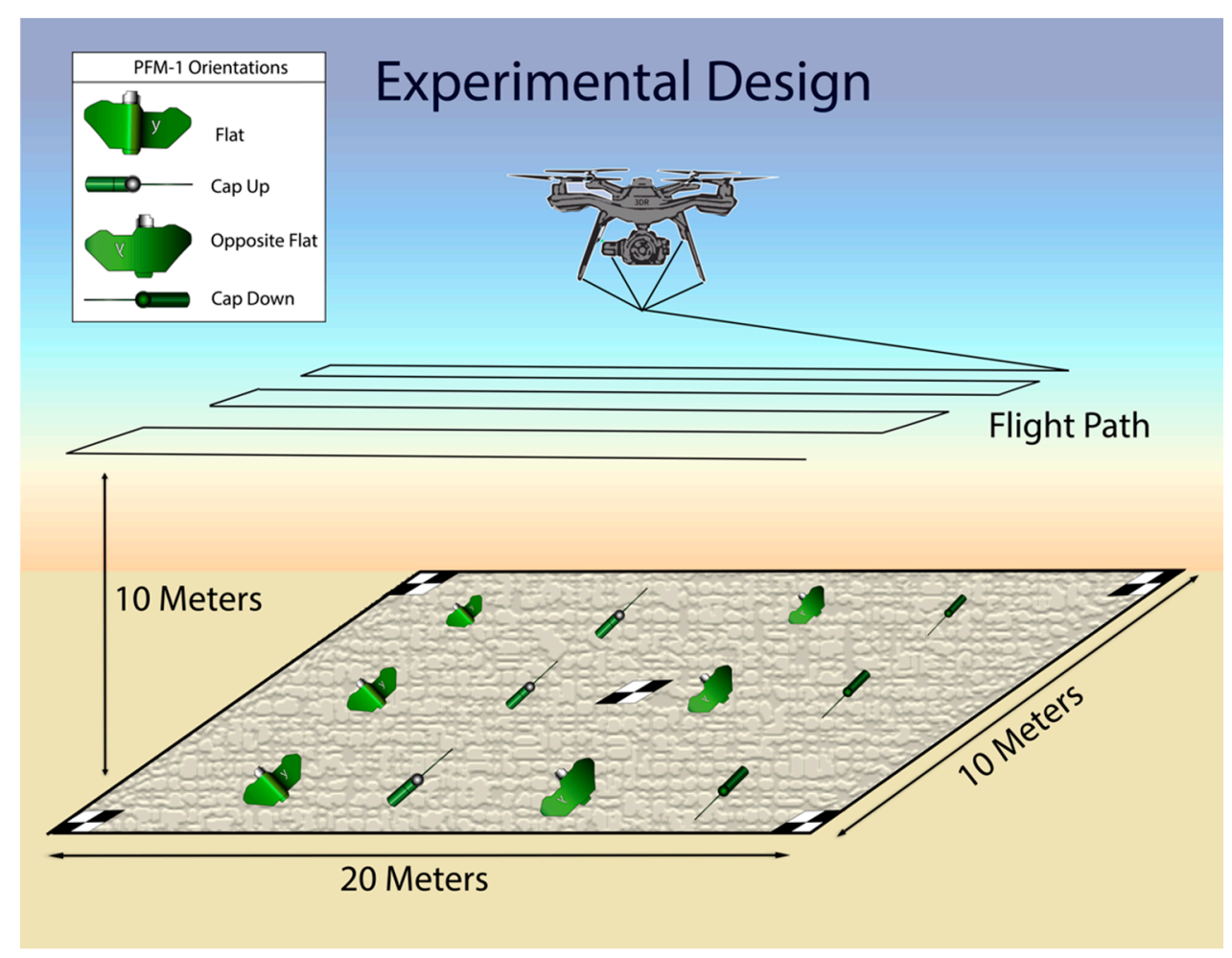

Figure 3. Experimental design and four orientations of PFM-1 landmines. 


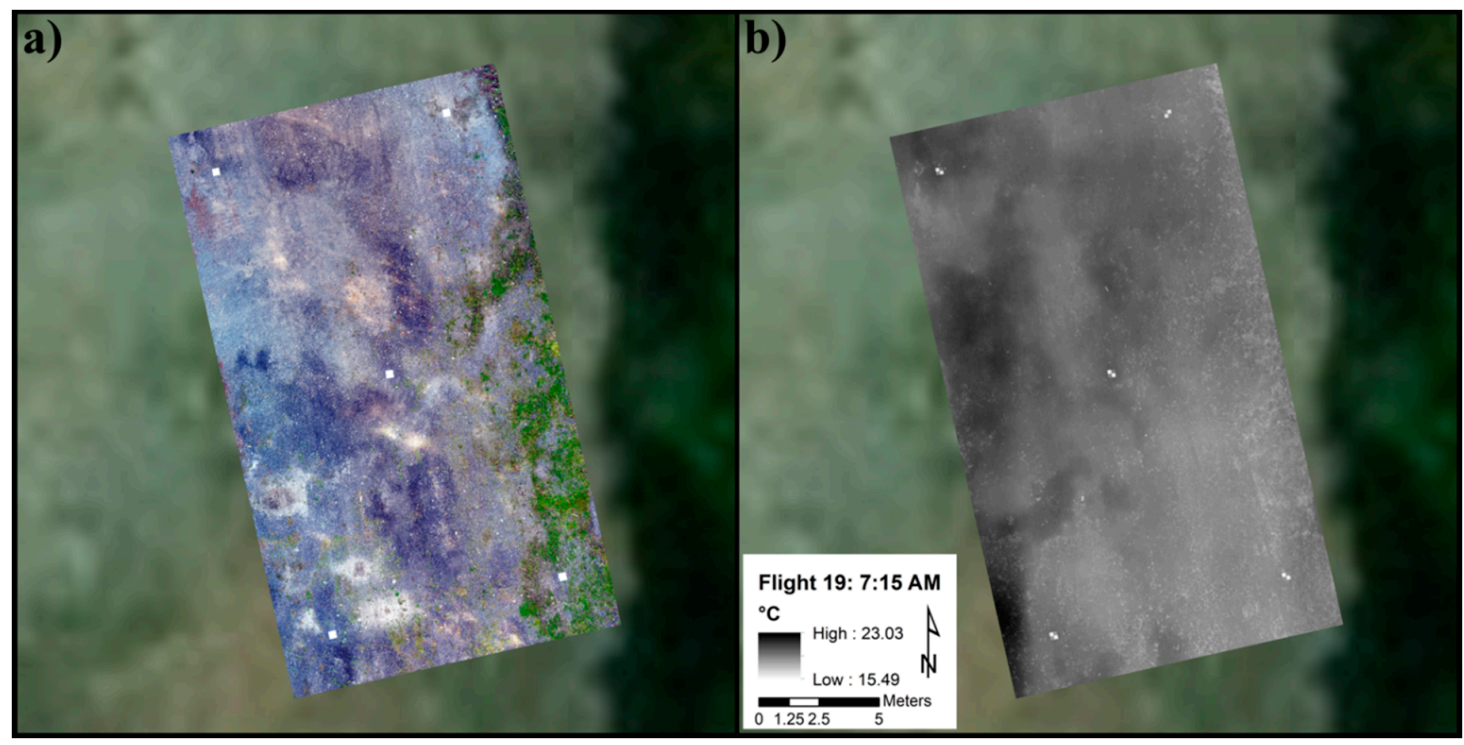

Figure 4. (a) Aerial photogrammetry from DJI Phantom 4 Professional 20-megapixel camera. (b) apparent temperature orthomosaic from 7:15 A.M. flight. Checkerboard aluminum-paint low-high emissivity ground control points (GCP) can be seen in the corners of the survey area (appearing as white dots). Tree line can be seen to the east (right).

Low-emissivity aluminum and high-emissivity paint checkerboard ground control point (GCP) targets were used during data acquisition to control horizontal spatial accuracy to the centimeter (Figure 4b) in pre-processing. A Trimble GeoXH $6 \mathrm{~cm}$ edition GNSS (Global Navigation Satellite System) antenna was used to collect centimeter-accurate global positioning data over the GCPs and subsequently georeference the radiometric temperature rasters. The images were pre-processed with ThermoViewer to produce 14-bit raster data sets and exported for photogrammetric processing in pix4Dmapper. The IR index orthomosaics were then converted to radiometric temperature rasters in degrees Celsius using the raster calculator tool in ESRI's ArcMap (Figure 4b). The DATI was also calculated in ${ }^{\circ} \mathrm{C} /$ hour using automated processing in $\mathrm{R}$ statistical computing software's raster package [56].

\section{Results}

Our datasets consist of visible light and LWIR apparent temperature orthomosaic rasters processed in pix4Dmapper and visualized in ArcMap 10 and are presented in Figures 5-7. The PFM-1 landmines and KSF-1 casing elements begin the day several degrees cooler than their environmental background in the early morning hours shortly after sunrise (Figures 5 and 6). The landmines likely remain cooler than their geological background in the early morning hours because the small plastic landmines do not retain temperature as well as their environmental host. Moreover, the apparent temperature of the aluminum KSF-1 casing elements is radiometrically inaccurately too cold since shiny aluminum has a low emissivity (Figure 6). This is important to note as the KSF-1 aluminum elements will always appear cooler than their surrounding environment and have a distinctive shape, making them easy to detect, identify, and classify.

A statistical analysis of four early morning flights yielded an average detection sensitivity rate of $77.88 \%$, where the detection threshold was set as two standard deviations from the mean. These flights occurred at 06:30, 06:45, 07:00, and 07:15, on the morning of 17 September. Detection sensitivity was determined using the following formula: sensitivity $=$ (number of true positives) $/$ (number of true positives + number of false negatives). This includes the detection of all 18 PFM-1 landmines and all components of their KSF-1 casing. Detection sensitivity ranged from $65.38 \%$ to $84.61 \%$ during these four flights, with 9 false positive detections occurring. Critically, all aluminum components of the 
KSF-1 casing were visually detected in each of these four trials, allowing for rapid characterization of the minefield's ballistic orientation.

The in-place geometry of the PFM-1 does not appear to affect the apparent temperature measurements as the landmines are easily visible in each of the four orientations examined in this study (Figure 5). This is not because of the emissivity properties of plastic, which unlike shiny aluminum are similar to the background geology. Rather, man-made materials like plastic have different physical properties like heat capacity and thermal conductivity to the natural background environment. This study demonstrates that surficial mines can be detected with LWIR regardless of their orientation, which is promising as PFM-1's are dispersed randomly and can be mobilized subsequent to initial emplacement.

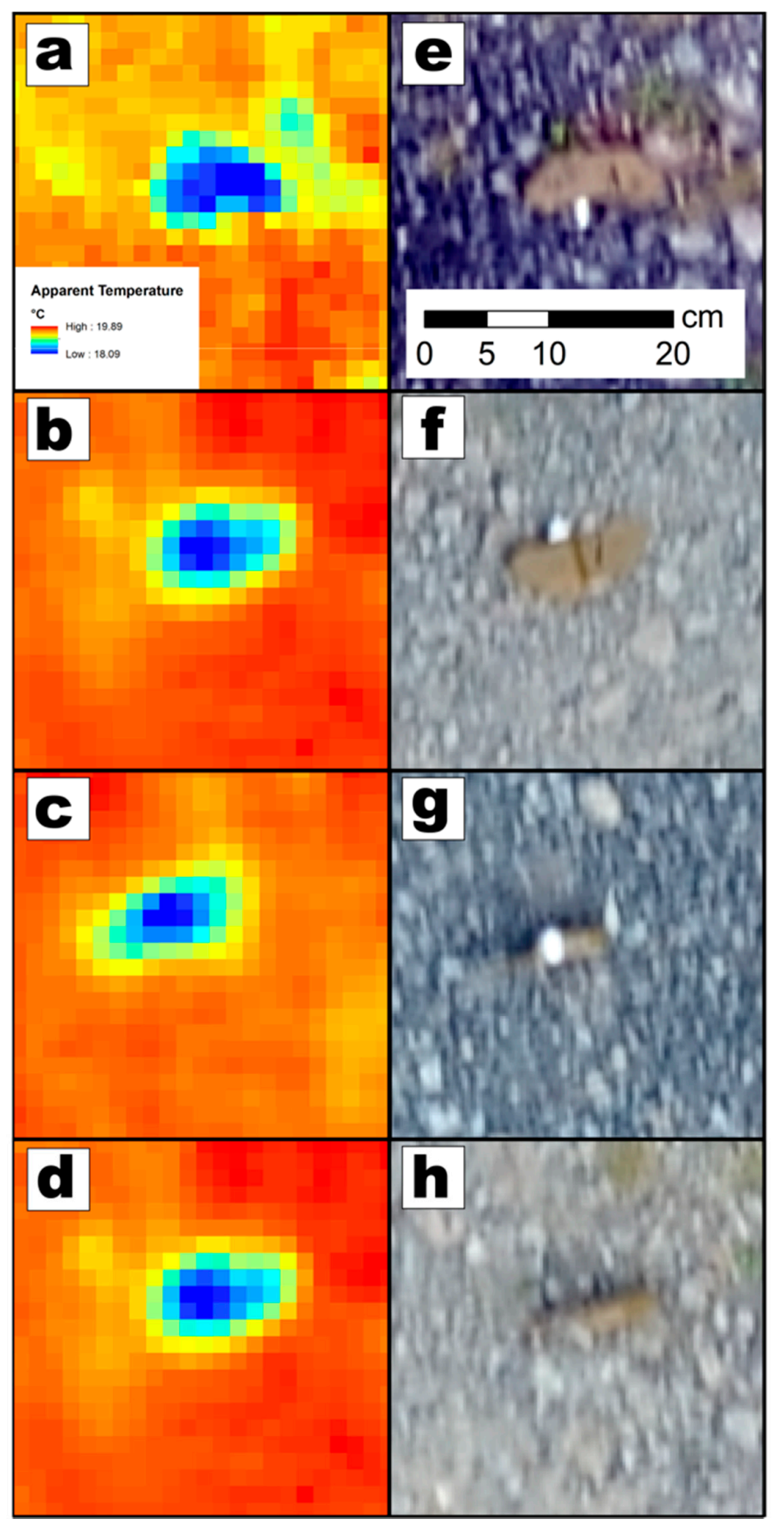

Figure 5. Apparent temperature of PFM-1 mines in (a) opposite flat, (b) flat, (c) cap up, and (d) cap down orientations at 6:45 A.M. Aerial photogrammetry model from mid-day flight of mines in (e) opposite flat, (f) flat, (g) cap up, and (h) cap down orientations. 


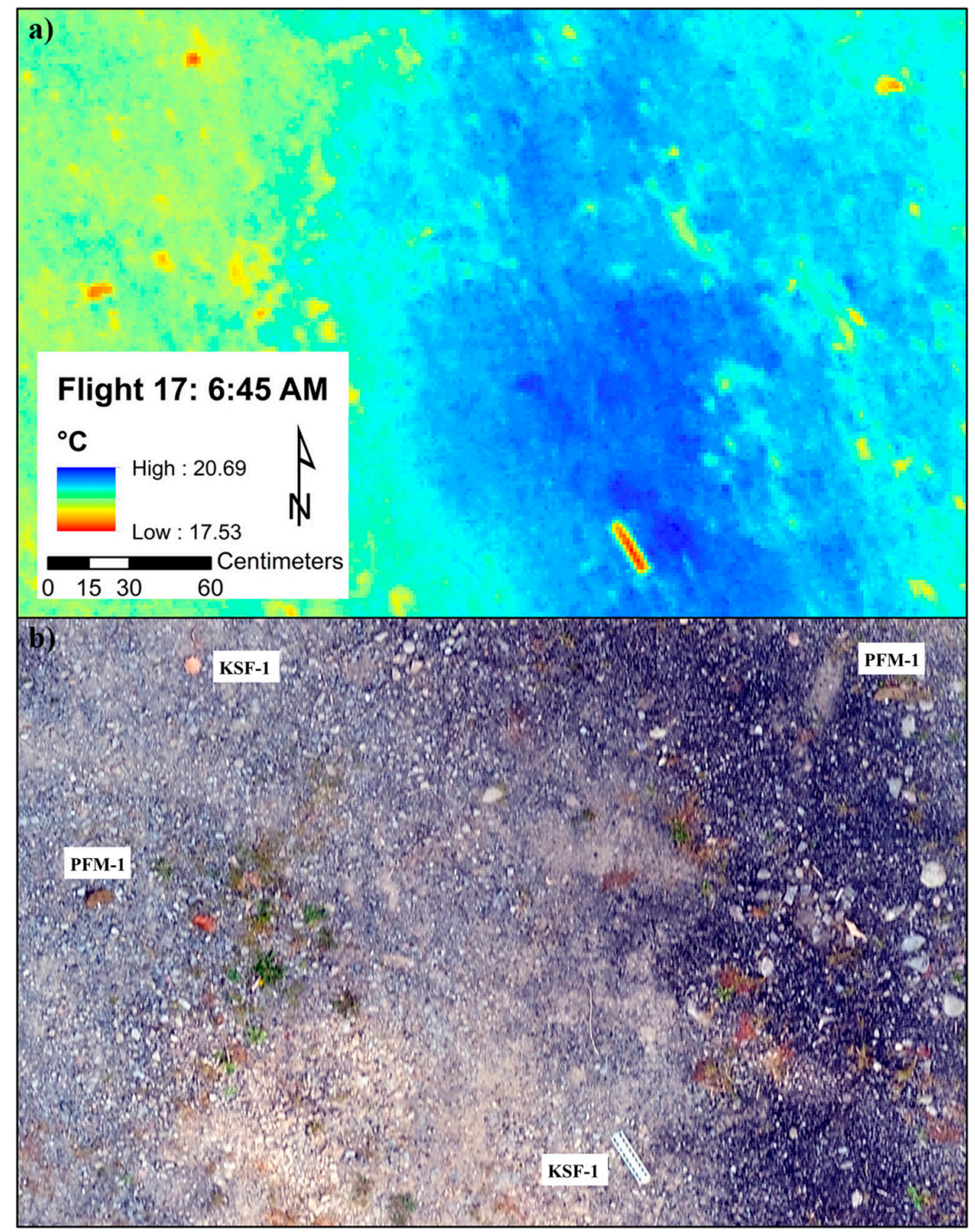

Figure 6. (a) Apparent temperature at 6:45 A.M. flight around sunrise, and (b) aerial photogrammetry over the same area.

In this study there is a slight delay in direct heating of the landmines due to the fact that 20-30 m tall trees bordered the eastern margin of our experimental survey area where the sun rises (Figure 3). The westernmost line of PFM-1 landmines was the easiest to visually detect in flights between 6:30 A.M. and 7:15 A.M. due to the effects of these large trees on the heating process. The landmines were not directly heated by the sun until several hours after sunrise at around 9 A.M. local time. The atmospheric temperature at 6:45 A.M. sunrise was $15^{\circ} \mathrm{C}$, but by $10 \mathrm{~A} . \mathrm{M}$. had risen to $21.1^{\circ} \mathrm{C}$. After receiving direct sunlight, the mines heat up rapidly compared to the host environment, as can be seen by their DATI over a short-term time-series of several flights (Figure 7). The DATI of shorter-term time-series provide a better constraint of the mines than longer-term time-series in these trials. The PFM-1 landmines begin the day cooler than their host environment, rapidly rise in temperature after direct heating from the sun relative to background, and subsequently equilibrate with their environment by midday.

The geological background, in this case modeled to represent an arid high-altitude environment, provides little interference and can be distinguished from a PFM-1 thermal signal. Stationary trials conducted by de Smet et al. [54] demonstrated that the orientation, moisture content, depth of burial, and host geological background can influence the detection capabilities of thermal imaging. Namely, increasing depth of burial, decreasing moisture content, and presence of geological and anthropogenic 
clutter limits the detection sensitivity of the protocol. Conversely, the mines are easiest to detect in fine-grain environments like sand, silt, or clay in the absence of vegetation and clutter. As a result, this method may have limited potential in or near urban areas and areas of dense vegetation cover. However, we point out that the rationale for PFM-1 mine deployment was precisely to block access to remote high-altitude areas, resulting in favorable parameters for remote thermal detection.

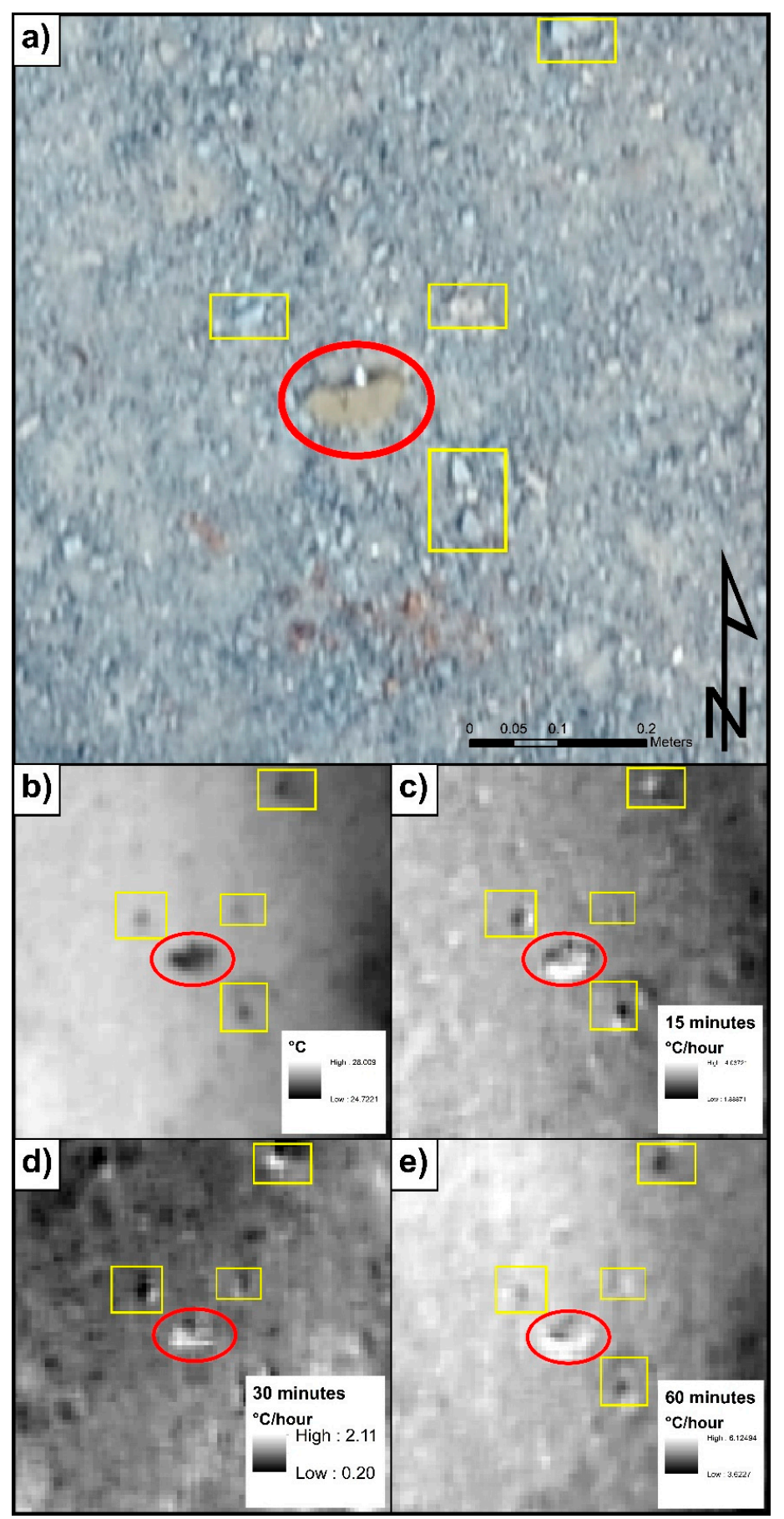

Figure 7. UAV image at $10 \mathrm{~m}$ above ground level of PFM-1 (shown in red oval) captured by (a) Visible light and (b) apparent temperature at 09:15, and differential apparent thermal inertia for short-term time-series at: (c) $15 \mathrm{~min}$, (d) $30 \mathrm{~min}$, and (e) $60 \mathrm{~min}$. Yellow rectangles indicate larger rocks as potential sources of thermal clutter, which can be discriminated in differential apparent thermal inertia (DATI) images. 


\section{Discussion}

The overarching question that this study attempted to address is whether it would be possible to replicate the success of our stationary DATI experiment in a dynamic trial with a UAV-mounted camera over an area similar in size to a ballistic PFM-1 minefield. Furthermore, we complicated the original set-up by introducing variable orientations to in-place PFM-1 mines to model a scenario where individual mines may be trapped between rocks upon descent or after subsequent remobilization driven by environmental forces. Our field trials results allow us to answer the central question of this study in an affirmative way. We show that careful flight planning and proper georeferencing allowed us to stabilize the acquired photogrammetry images and DATI and discern individual PFM-1 mine elements with a high degree of accuracy. In our trials we were consistently able to identify the 18 inert mines and their KSF-1 casing components with a 77.88\% overall detection sensitivity, and a $100 \%$ detection rate of the metal components of the KSF-1 casing.

Application of our methodology may be impacted by variations in surface geology, specific temperature conditions of the host environment and any sediment cover developing over the minefields since their initial dispersal. Additional tests and calibrations are needed, and we look forward to additional field trials in areas with similar environmental conditions to our ultimate target areas of mountainous Afghanistan. Previously-conducted controlled experiments tested environmental variables influencing PFM-1 detection and identification accuracy, specifically moisture content, orientation of the landmine, depth of burial, vegetation cover, time of day and host geology (de Smet et al.). These experiments demonstrated that in areas of higher moisture content there are greater temperature contrasts between the PFM-1 and the surrounding sand and cobble environment. We attribute this to higher thermal diffusivity of the host geology $[50,52,54]$. In regions of relatively low moisture content, thermal detection is still viable, but the temperature differential between the mines and surrounding environment is reduced. This is a significant detection-determining factor to consider in the context of Afghanistan, where precipitation averages $\sim 327 \mathrm{~mm}$ a year, varying by region and season [57].

The de Smet et al. [54] study further investigated how host environmental materials including sand, grass and cobble-sized environments effect detection of the PFM-1. As hypothesized, detection of the mines in the sand environment was much easier than in the cobble environment as the cobble sized rocks increased the likelihood of false positives in thermal infrared detection. Lastly, the optimal time of day for detection was determined to be 30-120 min after sunrise and sunset for DATI, and from 12:00-14:00 during peak sunlight hours for raw thermal images [55]. Finally, randomized deployment tests conducted as part of this study demonstrated that due to the characteristic "butterfly" shape of the PFM-1, it is most likely to lay in a horizontal position, exposing the greatest amount of visible surface area. for aerial detection. When the PFM-1s were buried at depths of 1,2, 3, and $4 \mathrm{~cm}$ or covered with vegetation, the thermal properties of the mines were masked by the overlaying soil, sediment or vegetation, making thermal differences insignificant and aerial thermal infrared detection difficult with current IR imagery capabilities [54].

We point out that we tested our method in a relatively stable temperature environment of Upstate New York and we expect much greater daily temperature variations in high-altitude arid regions, potentially yielding an even stronger DATI signal associated with PFM-1. Furthermore, our positive results would be dramatically impacted by the presence of plastic debris or metal fragments similar in thermal signature to the PFM-1 or the aluminum KSF-1 casing. However, we specifically target our methodology for use in remote high-altitude areas, where the initial use of PFM-1 mines was largely driven by inaccessibility of these areas to regular engineering units. As such, we expect minimal anthropogenic clutter in our field sites and have not introduced it as a factor in our experiments. 


\section{Conclusions}

The declining cost of sensors [58] and rapid development of smaller commercial UAV technology [59] has enabled new approaches to the problem of landmine identification and clearing. To date, we have developed and field-tested a UAV-based thermal-imaging system that allows analysis of a $200 \mathrm{~m}^{2}$ area in a single nine-minute flight and reliably locates any scattered PFM-1 landmines present within this area. While this method is not meant to fully replace or substitute on-the-ground mine clearing operations, its demonstrated strength is in the ability to rapidly detect (a) PFM-1 mine presence, (b) PFM-1 minefield orientation, (c) PFM-1 field overlap, and, as a result, dramatically constrain the search area for ultimate demining. The relatively low initial cost of the UAV system, coupled with cost savings associated with search area reduction and reduced operator risk, demonstrate the promise of this emerging method.

Our results demonstrate that the integration of several low-cost out-of-the-box technologies can be used to improve the efficiency of detecting man-made thermal anomalies. In subsequent field trials we anticipate significantly increasing our search area by using UAVs with expanded flight times and greater payload to allow for longer data collection over wider areas. We will also further our inquiry into long-term environmental factors that may impact detection, such as seasonal temperature and moisture variations. Finally, as this research effort progresses, we anticipate using the large image datasets to develop an automated algorithm that can be used in machine-assisted detection. In all, the presented methodological approach to detection and identification of small aerially-deployed plastic landmines has the potential to significantly improve efficiency and reduce costs associated with clearing remote areas impacted by the PFM-1 landmine crisis.

Author Contributions: A.N. and T.S.d.S. developed the methodology used in the study, designed the experiment, and supervised the research team. J.B., W.D.F., and J.C.A. contributed to data curation, analysis and visualization of the results of the experiments. All co-authors contributed to original draft preparation and review and editing.

Funding: This project was supported by funds provided by Binghamton University through the Freshman Research Immersion Program and new faculty start-up funds for Alex Nikulin.

Acknowledgments: We would like to thank students in the Freshman Research Immersion Geospatial Remote Sensing research stream at Binghamton University. This work was conducted under New York State Parks Unmanned Aircraft and Special Use permits and we extend our gratitude to park manager Michael Boyle and all staff of the Chenango Valley State Park for their assistance with this project. This project was supported in part by grants to Binghamton University from the following: Howard Hughes Medical Institute through the Precollege and Undergraduate Science Education Program, New York State Regional Economic Development Council, and SUNY Investment and Performance Program. We extend our gratitude to the four anonymous reviewers for their insightful comments and suggestions that greatly strengthened this manuscript.

Conflicts of Interest: The authors have no conflicts of interest.

\section{References}

1. Bello, R. Literature review on landmines and detection methods. Front. Sci. 2013, 3, 27-42.

2. Roberts, S.; Williams, J. After the Guns Fall Silent: The Enduring Legacy of Landmines; Oxfam: Oxford, UK, 1995.

3. Bruschini, C.; Gros, B.; Guerne, F.; Piece, P.Y.; Carmona, O. Ground penetrating radar and imaging metal detector for antipersonnel mine detection. J. Appl. Geophys. 1998, 40, 59-71. [CrossRef]

4. Gooneratne, C.P.; Mukhopahyay, S.C.; Gupta, G.S. A review of sensing technologies for landmine detection: Unmanned vehicle based approach. In Proceedings of the 2nd International Conference on Autonomous Robots and Agents, Palmerston North, New Zealand, 13-15 December 2004; pp. 401-407.

5. Schreiner, K. Landmine detection research pushes forward, despite challenges. IEEE Intell. Syst. 2002, 17, 4-7. [CrossRef]

6. Stover, E.R.I.C.; Cobey, J.C.; Fine, J. The public health effects of land mines: Long-term consequences for civilians. War Public Health 1997, 137-146.

7. Dolgov, R. Landmines in Russia and the Former Soviet Union: A Lethal Epidemic. Med. Glob. Surviv. 2001, 7, $38-42$. 
8. Fraser, M. Landmines: An ongoing environmental health problem for the children of Afghanistan. J. Rural Remote Environ. Health 2003, 2, 76-89.

9. Strada, G. The horror of land mines. Sci. Am. 1996, 274, 40-45. [CrossRef]

10. Urban, M. Nine: 1986. In War in Afghanistan; Palgrave Macmillan: London, UK, 1990; pp. 186-211.

11. De Smet, T.; Nikulin, A. Catching "butterflies" in the morning: A new methodology for rapid detection of aerially deployed plastic land mines from UAVs. Lead. Edge 2018, 37, 367-371. [CrossRef]

12. Hughes, G. The Soviet-Afghan War, 1978-1989: An Overview. Defence Stud. 2008, 8, 326-350. [CrossRef]

13. Harutyunyan, A. Demining in Remote Areas of Northern Afghanistan. J. Conv. Weapons Destr. 2014, 18, 10.

14. MacDonald, J.; Lockwood, J.R.; McFee, J.; Altshuler, T.; Broach, T. Alternatives for Landmine Detection; No. RAND/MR-1608-OSTP; Rand Corp: Santa Monica, CA, USA, 2003.

15. Harmon, R.S.; DeLucia, F.C.; LaPointe, A.; Winkel, R.J.; Miziolek, A.W. LIBS for landmine detection and discrimination. Anal. Bioanal. Chem. 2006, 385, 1140-1148. [CrossRef] [PubMed]

16. Asch, T.; Moulton, C.; Smith, D.V. Classification of MEC with the ALLTEM at Camp Stanley, Texas. In Proceedings of the 81st Annual International Meeting, San Antonio, TX, USA, 18-22 September 2011; pp. 1363-1367. [CrossRef]

17. Igel, J.; Preetz, H.; Takahashi, K.; Loewer, M. Landmine and UXO detection using EMI and GPR-limitations due to the influence of the soil. First Break 2013, 31, 43-51.

18. Daniels, D.J. Ground penetrating radar. In Encyclopedia of RF and Microwave Engineering; Wiley: Hoboken, NJ, USA, 2005.

19. Metwaly, M. Detection of metallic and plastic landmines using the GPR and 2-D resistivity techniques. Nat. Hazards Earth Syst. Sci. 2007, 7, 755-763. [CrossRef]

20. Daniels, D.J. Ground penetrating radar for buried landmine and IED detection. In Unexploded Ordnance Detection and Mitigation; Springer: Dordrecht, The Netherlands, 2009; pp. 89-111.

21. Giannakis, I.; Xu, S.; Aubry, P.; Yarovoy, A.; Sala, J. Signal processing for landmine detection using ground penetrating radar. In Proceedings of the 2016 IEEE International Geoscience and Remote Sensing Symposium (IGARSS), Beijing, China, 10-15 July 2016; pp. 7442-7445.

22. Lombardi, F.; Griffiths, H.D.; Wright, L.; Balleri, A. Dependence of landmine radar signature on aspect angle. IET Radar Sonar Navig. 2017, 11, 892-902. [CrossRef]

23. Zanzi, L.; Lualdi, M.; Braun, H.M.; Borisch, W.; Triltzsch, G. Ultrahigh-frequency radar sensor for humanitarian demining tested on different scenarios in 3D imaging mode. In Proceedings of the Ninth International Conference on Ground Penetrating Radar, Santa Barbara, CA, USA, 29 April-2 May 2002.

24. Walls, R.; Brown, T.; Clodfelter, F.; Coors, J.; Laudato, S.; Lauziere, S.; Patrikar, A.; Poole, M.; Price, M. Ground penetrating radar field evaluation in Angola. In Proceedings of the Detection and Remediation Technologies for Mines and Minelike Targets XI, Orlando, FL, USA, 17-21 April 2006; International Society for Optics and Photonics: Bellingham, WA, USA, 2006; Volume 6217.

25. Lualdi, M.; Lombardi, F. Combining orthogonal polarization for elongated target detection with GPR. J. Geophys. Eng. 2014, 11, 055006. [CrossRef]

26. Paglieroni, D.W.; Chambers, D.H.; Mast, J.E.; Bond, S.W.; Beer, N.R. Imaging modes for ground penetrating radar and their relation to detection performance. IEEE J. Sel. Top. Appl. Earth Obs. Remote Sens. 2015, 8, 1132-1144. [CrossRef]

27. Sabatier, J.M.; Xiang, N. An investigation of acoustic-to-seismic coupling to detect buried anti-tank landmines. IEEE Trans. Geosci. Remote Sens. 2001, 39, 1146-1154. [CrossRef]

28. Xiang, N.; Sabatier, J.M. An experimental study on antipersonnel landmine detection using acoustic-to-seismic coupling. J. Acoust. Soc. Am. 2003, 113, 1333-1341. [CrossRef] [PubMed]

29. Donskoy, D.; Ekimov, A.; Sedunov, N.; Tsionskiy, M. Nonlinear seismo-acoustic land mine detection and discrimination. J. Acoust. Soc. Am. 2002, 111, 2705-2714. [CrossRef] [PubMed]

30. Zagrai, A.; Donskoy, D.; Ekimov, A. Structural vibrations of buried land mines. J. Acoust. Soc. Am. 2005, 118, 3619-3628. [CrossRef]

31. Kasban, H.; Zahran, O.; El-Kordy, M.; Elaraby, S.M.; El-Samie, F.A. Automatic object detection from acoustic to seismic landmine images. In Proceedings of the 2008 International Conference on Computer and Engineer systems, Cairo, Egypt, 25-27 November 2008; pp. 193-198. 
32. Cherkauer, K.A.; Burges, S.J.; Handcock, R.N.; Kay, J.E.; Kampf, S.K.; Gillespie, A.R. Assessing satellite-based and aircraft based remote thermal infrared remote sensing for monitoring Pacific Northwest river temperature 1. J. Am. Water Resour. Assoc. 2005, 41, 1149-1159. [CrossRef]

33. Zappa, C.J.; Jessup, A.T. High-resolution airborne infrared measurements of ocean skin temperatures. IEEE Trans. Geosci. Remote 2005, 2, 146-150. [CrossRef]

34. Yu, Y.; Rothrock, D.A. Thin ice thickness from satellite thermal imagery. J. Geophys. Res. Oceans 1996, 101, 25753-25766. [CrossRef]

35. Rivoire, L.; Birner, T.; Knaff, J.A. Evolution of the upper-level thermal structure in tropical cyclones. Geophys. Res. Lett. 2016, 43, 10530-10537. [CrossRef]

36. Kossin, J.P.; Knaff, J.A.; Berger, H.I.; Herndon, D.C.; Cram, T.A.; Velden, C.S.; Murnane, R.J.; Hawkins, J.D. Estimating Hurricane Wind Structure in the Absence of Aircraft Reconnaissance. Weather Forecast. 2007, 22, 89-101. [CrossRef]

37. Naugle, D.E.; Jenks, J.A.; Kernohan, B.J. Use of thermal infared sensing to estimate density of white-tailed deer. Wildl. Soci. Bull. 1996, 24, 37-43.

38. Ortega-Farias, S.; Ortega-Salazar, S.; Poblete, T.; Kilic, A.; Allen, R.; Polblete-Echeverria, C.; Ahumada-Orellana, L.; Zungia, M.; Sepulveda, D. Estimation of Energy Balance Components over a Drip-Irrigated Olive Orchard Using Thermal and Multispectral Cameras Placed on a Helicopter-Based Unmanned Aerial Vehicle (UAV). Remote Sens. 2016, 8, 638. [CrossRef]

39. Bendig, J.; Yu, K.; Aasen, H.; Bolten, A.; Bennertz, S.; Broscheit, J.; Gnyp, M.L.; Bareth, G. Combining UAV-based plant height from crop surface models, visible, and near infrared vegetation indices for biomass monitoring in barley. Int. J. Appl. Earth Obs. Geoinf. 2015, 39, 79-87. [CrossRef]

40. Sepuleda-Reyes, D.; Ingram, B.; Bardeen, M.; Zungia, M.; Ortega-Farias, S.; Poblete-Echeverria, C. Selecting Canopy Zones and Thresholding Approaches to Assess Grapevine Water Status by Using Aerial and Ground-Based Thermal Imaging. Remote Sens. 2016, 8, 622.

41. Bellvert, J.; Zarco-Tejada, P.J.; Girona, J.; Fereres, E. Mapping crop water stress index in a 'Pinot-noir' vineyard: Comparing ground measurements with thermal remote sensing imagery from an unmanned aerial vehicle. Precis. Agric. 2014, 15, 361-376. [CrossRef]

42. Sparks, R.S.J.; Biggs, J.; Neuberg, J.W. Monitoring Volcanoes. Science 2012, 335, 1310-1311. [CrossRef] [PubMed]

43. McGonigle, A.J.S.; Aiuppa, A.; Giudice, G.; Tamburello, G.; Hodson, A.J.; Gurrieri, S. Unmanned aerial vehicle measurements of volcanic carbon dioxide fluxes. Geophys. Res. Lett. 2008, 35. [CrossRef]

44. Poirier, N.; Hautefeuille, F.; Calastrenc, C. Low Altitude Thermal Survey by Means of an Automated Unmanned Aerial Vehicle for the Detection of Archaeological Buried Structures. Archeol. Prospect. 2013, 20, 303-307. [CrossRef]

45. Giardini, M.J. A history of NASA remote sensing contribution to archaeology. J. Archeol. Sci. 2011, 38, 2003-2009. [CrossRef]

46. Pajares, G. Overview and Current Status of Remote Sensing Applications Based on Unmanned Aerial Vehicles (UAVs). Photogramm. Eng. Remote Sens. 2015, 81, 281-330. [CrossRef]

47. Price, S.R.; Anderson, D.T.; Luke, R.H.; Stone, K.; Keller, J.M. Automatic detection system for buried explosive hazards in FL-LWIR based on soft feature extraction using a bank of Gabor energy filters. In Proceedings of the SPIE 8709, Detection and Sensing of Mines, Explosive Objects, and Obscured Targets XVIII, Baltimore, MD, USA, 29 April-3 May 2013.

48. Popescu, M.; Paino, A.; Stone, K.; Keller, J.M. Detection of Buried Objects in FLIR Imaging Using mathematical morphology and SYV. In Proceedings of the 2012 IEEE Symposium on Computational Intelligence for Security and Defence Applications (CISDA), Ottawa, ON, Canada, 11-13 July 2012; pp. 1-5.

49. Yao, F.; Shao, G.; Sekmen, A.; Malkani, M. Real-Time Multiple Moving Targets Detection from Airborne IR Imagery by Dynamic Gabor Filter and Dynamic Gaussian Detector. EURASIP J. Image Video Process. 2010, 2010, 124681. [CrossRef]

50. Deans, J.; Gerhard, J.; Carter, L.J. Analysis of a thermal imaging method for landmine detection, using infrared heating of the sand surface. Infrared Phys. Technol. 2006, 48, 202-216. [CrossRef]

51. Thành, N.T.; Sahli, H.; Hào, D.N. Infrared Thermography for Buried Landmine Detect: Inverse Problem Setting. IEEE Trans. Geosci. Remote Sens. 2008, 46, 3987-4004. [CrossRef] 
52. Smits, K.M.; Cihan, A.; Sakaki, T.; Howington, S.E. Soil Moisture and Thermal Behavior in the Vicinity of Buried Objects Affecting Remote Sensing Detection. IEEE Trans. Geosci. Remote Sens. 2013, 51, 2675-2688. [CrossRef]

53. Agarwal, S.; Sriram, P.; Palit, P.P.; Mitchell, O.R. Algorithms for IR-imagery-based airborne landmine and minefield detection. In Proceedings of the SPIE-Detection and Remediation of Mine and Minelike Targets VI, Orlando, FL, USA, 16-20 April 2001; Volume 4394, pp. 284-295.

54. De Smet, T.S.; Nikulin, A.; Frazer, W.; Baur, J.; Abramowitz, J.; Finan, D.; Aglietti, N. Drones and "Butterflies": A low cost UAV System for Rapid Detection and Identification of Unconventional Minefields. J. Conv. Weapons Destr. 2018, 22. in press.

55. Sabol, D.E.; Gillespie, A.R.; McDonald, E.; Danillina, I. Differential thermal inertia of geological surfaces. In Proceedings of the 2nd Annual International Symposium of Recent Advances in Quantitative Remote Sensing, Torrent, Spain, 25-29 September 2006; pp. 25-29.

56. Hijmans, R.J.; van Etten, J. Raster: Geographic Analysis and Modeling with Raster Data; R Package Version 2.0-12; R Foundation: Vienna, Austria, 2017.

57. World Bank. Average Precipitation in Depth (mm per Year); Food and Agriculture Organization: Rome, Italy, 2014.

58. Pantuso, F.P. The path to affordable and available 640x480 uncooled FPAs. In Proceedings of the Infrared Technology and Applications XXXI, Orlando, FL, USA, 28 March-1 April 2005; pp. 539-544.

59. Alford, B.; Curran, E.; Cole, S. Determining the Value of UAVs in Iraq. J. Conv. Weapons Destr. 2018, 22, 8.

(C) 2018 by the authors. Licensee MDPI, Basel, Switzerland. This article is an open access article distributed under the terms and conditions of the Creative Commons Attribution (CC BY) license (http:/ / creativecommons.org/licenses/by/4.0/). 